\title{
Angústia e coragem de desespero na literatura modernista de Fernando Pessoa
}

\author{
Ivanilton Aragão de Moura*
}

\begin{abstract}
RESUMO
Em A Coragem de Ser (1952), Tillich define o conceito de coragem como o ato de autoafirmação do ser diante da ameaça do não-ser. Ele percebia também na arte existencialista do século XX expressões da angústia da insignificação, resultando no desespero enquanto tentativa de incorporar tal angústia à coragem de ser como si próprio. A consciência da finitude que alimenta a angústia leva ao desespero em face da inevitável vitória do não-ser materializada na morte. A discussão aqui se dirige ao questionamento da literatura modernista a partir da obra de Fernando Pessoa. Ao compreender o humano do século XX como alguém que perdeu o centro significante do mundo, Tillich nos permite analisar a arte considerando as implicações da virada filosófica que se impõe com a filosofia de Nietzsche, em sua declaração da morte de Deus. Se a nietzschiana morte de Deus resulta no que Heidegger chamou de fim da metafísica, os desdobramentos dessas ideias, quando visíveis na literatura do século XX, em obras como a de Pessoa, podem nos apontar a literatura modernista como uma arte que se edifica no desespero humano frente à vacuidade de Deus? Se essa literatura se alimenta liricamente da angústia e manifesta a sua coragem na medida em que se assume desesperada, como repensar a relação entre religião e arte? Estas são algumas questões que dão prosseguimento a inquietações de pesquisa resultantes da minha dissertação de mestrado acerca da estética pessoana sob a análise religiosa da arte feita por Tillich.
\end{abstract}

Palavras-chave: Paul Tillich. Religião. Literatura. Modernismo. Fernando Pessoa.

* Graduado em Letras Português pela Universidade Federal de Sergipe (DLEV-UFS); Mestre em Ciências da Religião pela Universidade Federal de Sergipe (PPGCR-UFS). E-mail: ivandearagao@gmail.com Currículo Lattes: http://lattes.cnpq.br/3547703026097104. https://orcid.org/0000-0002-4451-5677 


\title{
ANXIETY AND COURAGE OF DESPAIR IN FERNANDO PESSOA'S MODERNIST LITERATURE
}

\begin{abstract}
In The Courage to Be (1952)) Tillich defines the concept of courage as the act of self-assertion of being in the face of the threat of non-being. He also perceived in twentieth-century existentialist art expressions of the anguish of meaninglessness, resulting in despair as an attempt to incorporate such anguish into the courage of being like oneself. The awareness of the finitude that feeds anguish leads to despair in the face of the inevitable victory of non-being, materialized in death. The discussion here addresses the questioning of modernist literature based on the work of Fernando Pessoa. By understanding the 20th century human as someone who has lost the significant center of the world, Tillich allows us to analyze art considering the implications of the philosophical turn imposed by Nietzsche's philosophy, in his declaration of the death of God. If the Nietzschean death of God results in what Heidegger called the end of metaphysics, the unfolding of these ideas, when visible in twentieth-century literature, in works such as Pessoa's, can point us to modernist literature as an art built on despair human face to the emptiness of God? If this literature feeds itself lyrically on anguish and expresses its courage as it becomes desperate, how can we rethink the relationship between religion and art? These are some questions that follow up on research concerns resulting from my master's thesis about the personal aesthetic under the religious analysis of art made by Tillich.
\end{abstract}

Keywords: Paul Tillich. Religion. Literature. Modernism. Fernando Pessoa.

\section{Introdução ${ }^{1}$}

Com o interesse de examinar um pouco mais a intrincada relação entre religião e literatura, este artigo se propõe a discutir as tendências modernistas da obra de Fernando Pessoa diante de um referencial teórico que considera conceitos importantes da obra de Paul Tillich. Os conceitos de coragem, angústia e desespero, presentes no livro $A$

Este artigo resulta de uma comunicação proferida no VIII Congresso da ANPTECRE, em setembro de 2021. É também a continuidade de inquietações de pesquisa que se desenvolveram no decorrer do meu mestrado, quando, dentre outras coisas, me dispus a realizar uma análise de alguns elementos da obra de Fernando Pessoa à luz do pensamento de Paul Tillich. 
Coragem de Ser (The Courage to Be, 1952), fornecem as mediações por meio das quais se pretende interpretar aqui a poesia modernista de Pessoa, especificamente naquilo em que ela se define como sensacionista. Sabe-se que o poeta português era um fecundo construtor de narrativas, não satisfeito com as narrativas feitas para definir suas personalidades poéticas, dedicou-se a construir um arcabouço conceitual capaz de justificar a variedade de sua perspectiva em seus horizontes de compreensão a respeito da literatura e da arte como um todo.

Colocando inquietações existenciais em primeiro plano, Pessoa parte do princípio de que "a arte real é encontrar o ponto exato de contato entre as coisas e a nossa interpretação delas” (PESSOA, 2015, p. 14). Como critério básico para essa interpretação, nós temos a sensação, representando toda a complexidade dos estímulos sensoriais na tarefa de fornecer as informações que, para ele, são as mais seguras quando se trata de apreender de alguma maneira a realidade do mundo. O sensacionismo, quando traduzido na obra poética, fica bem representado em versos como os que podemos ler a seguir, atribuídos ao heterônimo Álvaro de Campos:

Sentir tudo de todas as maneiras, Viver tudo de todos os lados,

Ser a mesma coisa de todos os modos possíveis ao mesmo tempo,

Realizar em si toda a humanidade de todos os momentos

Num só momento difuso, profuso, completo e longínquo. (...)

(PESSOA, 2020c, p. 1021)

Ou ainda quando o heterônimo Alberto Caeiro escreve:

Há metafísica bastante em não pensar em nada. (...)

O mistério das coisas? Sei lá o que é mistério!

O único mistério é haver quem pense no mistério. (...)

Porque a luz do sol vale mais que os pensamentos

De todos os filósofos e de todos os poetas. (...)

Metafísica? Que metafísica têm aquelas árvores?

A de serem verdes e copadas e de terem ramos

E a de dar fruto na sua hora, o que não nos faz pensar,

A nós, que não sabemos dar por elas. (...) 
O único sentido íntimo das coisas

É elas não terem sentido íntimo nenhum.

Não acredito em Deus porque nunca o vi.

Se ele quisesse que eu acreditasse nele,

Sem dúvida que viria falar comigo

E entraria pela minha porta dentro

Dizendo-me, Aqui estou! (...)

(PESSOA, 2020c, p. 678-679)

Nosso objetivo é justamente colocar a atenção na análise do ideal estético que produz essa valorização da sensação, nos desdobramentos possíveis de se entender como este ideal, resumido sob o rótulo de sensacionismo, traz para o modernismo português uma perspectiva desesperançada do mundo ao insistir em uma rejeição a tudo que venha de fontes metafísicas, num desespero que, em certa medida, pode ser compartilhado por todo o modernismo, quando interpreta o mundo à luz de uma percepção pós-morte de Deus. O investimento argumentativo aqui materializado aponta para a ideia de que existe ainda muito o que discutir quando se trata da relação entre religião e literatura, mais precisamente a literatura modernista e a sua relevância enquanto expressão artística depositária da angústia da vacuidade e insignificação, da qual Tillich fala em A Coragem de Ser.

A primeira parte do texto é dedicada ao arcabouço teórico de Tillich, especialmente no que diz respeito às relações entre religião e arte, com destaque para a abordagem dos conceitos de coragem e angústia, quando se analisa o cenário cultural e filosófico do início do século XX. No tópico seguinte, a discussão se encaminha para os elementos que fazem desse período um dos momentos mais filosoficamente cruciais para se entender a produção artística que desemboca no modernismo. Trata-se especificamente da relevância do anúncio da morte de Deus, feito por Nietzsche, quando se busca compreender as transformações culturais dessa época e os desdobramentos que nos conduzem a pensar o desespero como elemento marcante na produção literária modernista. A terceira parte se volta para o modernismo português, exatamente no que gira em torno do sensacionismo de Pessoa, enquanto um desenvolvimento teórico que orienta as escolhas estéticas de sua produção 
heteronímica ${ }^{2}$. Por fim, na conclusão existe o alinhamento das ideias que sugerem a poesia pessoana como uma literatura movida pela coragem de desesperar.

\section{Religião, coragem e angústia}

Em sua Teologia Sistemática, Tillich (2019, p. 552) entende a moralidade, a cultura e a religião como elementos constituintes da unidade do espírito ou ainda como funções da vida sob a dimensão do espírito, de maneira que se pode compreender as distinções entre tais elementos sem que se possa conceber uma separação definitiva entre eles. A moralidade, entendida como "constituição da pessoa como pessoa no encontro com outras pessoas" (TILLICH, 2019, p. 552) está intimamente entrelaçada com a religião e a cultura. Numa síntese elucidativa, poderíamos dizer que a cultura é a provedora dos conteúdos morais, responsável pela consolidação de ideais e valores de interesse da comunidade, enquanto a religião confere a urgência de uma incondicionalidade que caracteriza o imperativo moral. Enxergamos então a profusão de sentido das formas culturais numa posição em que, inevitavelmente, carrega em si vinculações com a moralidade e a religião.

Quando se compreende o papel do imperativo moral sob a incondicionalidade conferida pela religião, é possível perceber a forma como a moralidade nos interpela e nos convence das diversas exigências comunitárias. É possível vislumbrar nessa interpelação o elemento religioso se manifestando como a "substância da cultura ou fundamento do qual vive a cultura" (TILLICH, 2019, p. 552). Tillich entende que cada ato moral carrega consigo a consequência de ser também um ato de autocriação cultural e autotranscendência religiosa, assim como, numa relação de unidade essencial, cada ato cultural se mantém como um ato de autointegração moral e autotranscendência religiosa. O que nos leva a concluir a impossibilidade de existir um ato religioso que não se manifeste também como um ato de autointegração moral e autocriação

2 Heterônimo é um termo bastante comum quando se trata da obra de Fernando Pessoa. Enquanto o pseudônimo é o nome pelo qual um autor esconde a sua verdadeira identidade, o heterônimo é uma identidade completamente fictícia, com biografia ficcional diversa do autor, algo como um personagem criado pelo poeta, com estilo próprio de escrita, opiniões e demais características bem distintas da personalidade do seu criador. 
cultural. A religião é definida neste contexto como "autotranscendência da vida sob a dimensão do espírito" (TILLICH, 2019, p. 553). Com esta definição no horizonte, lemos em suas palavras: "não existe autotranscendência sob a dimensão do espírito sem a constituição do eu moral pelo imperativo incondicional, e essa autotranscendência só pode ganhar forma dentro do universo de sentido criado no ato cultural" (TILLICH, 2019, p. 552-553).

Enquanto a cultura lida com a criação dos sentidos de mundo que a moral irá organizar em hábitos ou expectativas de conduta comunitária, a religião é a orientação à transcendência da vida, fator que legitima a urgência das expectativas morais. A respeito da vida, Tillich admite a sua "mescla ambígua de elementos essenciais e existenciais" (TILLI$\mathrm{CH}, 2019$, p. 553), numa ambiguidade que afeta as três funções. Ao mencionar o conceito ontológico de vida como a "efetividade do ser" (TILLICH, 2019, p. 475), ele busca conciliar as qualificações essenciais e existenciais do ser em um conceito que possa abranger a mistura dessas qualificações. A potencialidade do ser manifesta o aspecto essencial de deter o poder de tornar-se efetivo, as condições pelas quais o ser se realiza como o que é, sem desconsiderar que a efetividade está sujeita às "condições da existência, como a finitude, a alienação, o conflito" (TILLICH, 2019, p. 476), seu aspecto existencial.

A religião, enquanto autotranscendência da vida "reivindica ser a resposta para as ambiguidades da vida em todas as outras dimensões" (TILLICH, 2019, p. 555), entretanto, ela mesma abriga profundas ambiguidades. Se podemos encontrar em todos os seres a disposição de lutar pela superação de suas limitações existenciais, ou ainda o ímpeto de alcançar a própria realização através das potencialidades essenciais, é no ser humano que temos essa disposição convertida numa esperança mais ou menos consciente por uma vida sem ambiguidades, uma vida que se eternize longe das garras existenciais e inevitáveis da morte. Sabemos que "é na religião que o ser humano começa a busca pela vida sem ambiguidade e é na religião que ele recebe a resposta" (TILLICH, 2019, p. 564), no entanto a natureza desta resposta é simbólica. Ao mesmo tempo em que a religião pode fornecer o consolo da finitude na crença de uma vida eterna vindoura, a porta para a eternidade prometida continua sendo a finitude da morte. 
Em A Coragem de Ser ${ }^{3}$, Tillich (1980, p. 34-36) nos diz que o ser carrega em si mesmo o não-ser. A coragem é definida como a autoafirmação do ser apesar daquilo que o ameaça de interromper a sua autoafirmação, por sua vez a angústia é justamente oriunda da consciência dessa relação constitutiva entre ser e não-ser, é estar consciente da possibilidade do não-ser, ou mais ainda, é a experiência de fim resultando da consciência da própria natureza finita. É possível dizer, portanto, que a angústia humana se caracteriza pela certeza de sua inevitável finitude. Mas se a experiência de transitoriedade do ser produz angústia na medida em que este se revela num processo vital ambíguo, e se a religião consiste na autotranscendência ansiosa por superar, simbolicamente, a ambiguidade que se sabe inevitável, como o ser humano que se vê no abandono da crença no absoluto pode empreender uma resposta satisfatória para a sua natureza angustiada?

Pensar o conceito tillichiano de coragem nos faz considerar a importância da relação eu-mundo, pois é diante do mundo que o eu realiza a sua autoafirmação, a partir da individualidade que se identifica pelo contraste em que se percebe distinta e separada de tudo. Os processos de individualização e participação podem ser correlacionados com as noções de eu e de mundo. Nesta perspectiva, participar consiste em "ser uma parte de algo do qual se está, ao mesmo tempo, separado. Literalmente, participação significa 'tomar parte'” (TILLICH, 1980, p. 88 - tradução nossa) ${ }^{4}$. O eu está contido no mundo e sujeito a toda dinâmica ambígua da existência nesses termos, ao mesmo tempo em que é pela distinção de si mesmo diante de tudo que a singularidade e a finitude do eu podem ser concebidas. Então é preciso que se pense a produção artística como manifestação de um eu quando tocado pelas intempéries de sua participação no mundo.

Quando se considera a relação entre religião e arte, a religião traz consigo o sentido de envolvimento com as questões últimas, de "ter levantado a pergunta acerca do 'ser ou não ser' em relação ao significado da própria existência e tendo símbolos pelos quais a questão é respondida" (TILLICH, 2020, p. 33). Para Tillich, o entendimento da

3 Título original: The Courage to Be.

4 "For this is just what participation means: being a part of something from which one is, at the same time, separated. Literally, participation means "taking part"”. 
arte moderna, do existencialismo e de muito do que se compreende como a cultura do século XX está condicionado ao devido entendimento da religião como "ser tocado de maneira última a respeito do próprio ser, a respeito de si mesmo e do mundo, a respeito do significado deste, de sua alienação e finitude" (TILLICH, 2020, p. 33).

É neste contexto que Tillich afirma que "a literatura e a arte fizeram da angústia o tema principal de suas criações, tanto no conteúdo quanto no estilo" (TILLICH, 1980, p. 35 - tradução nossa) ${ }^{5}$, posto que, seja na superfície ou na profundidade de seus discursos, as questões últimas compõem o cerne de toda produção literária de relevância crítica no século XX. O cenário das duas grandes guerras que abalaram o século passado teria produzido duas experiências distintas na cultura: a Primeira Guerra teria despertado um sentimento de recomeço, enquanto a Segunda Guerra traria a amargura de uma experiência de fim. A Teologia da Cultura seria uma Teologia do Fim da Cultura, na medida em que se dedica a uma análise do vazio inerente à maioria das expressões culturais desse período (TILLICH, 1990, p. 202) .

Em sua percepção do contexto artístico da primeira metade do século XX, Tillich identifica algumas características marcantes do ser humano que se apresenta com o advento da sociedade industrial, com destaque para a "transformação técnica do mundo", fator que ocasionou a "consequente perda da dimensão da profundidade no encontro com a realidade" (TILLICH, 2009, p. 84). Essa análise considera as transformações profundas que a era moderna nos trouxe, principalmente diante das turbulentas modulações que marcaram as quatro grandes narrativas da humanidade nesse período: o cristianismo, o iluminismo, o marxismo e o capitalismo. Com a notória reestruturação de paradigmas sob a influência do ímpeto utilitarista, técnico e pragmático da indústria, pudemos perceber um ajuste da esfera subjetiva da vida aos valores oriundos dessa nova dinâmica social que se firmou, trazendo consequências que reverberaram também nos domínios da religião.

\footnotetext{
5 "Literature and art have made anxiety a main theme of their creations, in content as well as in style."

6 "While after the first World War the mood of a new beginning prevailed, after the second World War a mood of the end prevails. A present ,theology of culture' is, above all, a theology of the end of culture, not in general terms, but in a concrete analysis of the inner void of most of our cultural expressions."
} 
A realidade "perdeu a transcendência interna ou, empregando outra metáfora, a transparência para o eterno" (TILLICH, 2009, p. 84-85), de maneira que a humanidade passou a ocupar o novo centro de um universo que tinha, na perspectiva do ocidente eurocêntrico, a figura do deus cristão como seu fundamento principal. Quando se refere ao lugar ocupado por Deus, Tillich reconhece as transformações do personagem divino desde o século XVIII, com a sua gradual perda de influência sobre as atividades humanas. "Dessa forma, Deus tornou-se supérfluo e nos tornamos mestres do universo" (TILLICH, 2009, p. 85), ressaltando aqui um importante dado desse período, o predomínio da humanidade sobre as instâncias criativas da vida. O trono de criador da realidade passa a ser ocupado pela criatura humana. Nessa conjuntura, o existencialismo pode ser visto como um ato de "protesto contra o espírito da sociedade industrial a partir dela mesma. O protesto dirige-se contra a posição do ser humano no sistema de produção e consumo" (TILLICH, 2009, p. 87). Pode-se perceber também uma crise de significação sem precedentes na nossa história, um desconforto existencial que em grande parte foi alimentado pela repercussão do evolucionismo de Darwin, um dos responsáveis pelo estremecimento de certas verdades religiosas no século XIX.

Achamos que somos mestres do mundo e de nós mesmos. Mas, na verdade, fazemos parte da realidade que criamos, objetos entre objetos, coisas entre coisas, parte da engrenagem da máquina universal à qual devemos nos adaptar para que ela não nos esmague. Essa adaptação nos transforma em meios para fins que também, por sua vez, são meios, sem finalidade alguma. Resultam daí experiências de vazio e falta de sentido, de desumanização e alienação. Não mais achamos sentido na realidade que, em suas formas e estruturas, nada nos diz. (TILLICH, 2009, p. 87)

A experiência de vazio presente na citação anterior nos leva ao conceito de "vazio sagrado", no qual Tillich (1990) aponta para uma vacuidade significativa, manifesta em algumas expressões culturais de vanguarda, como o expressionismo e o neorrealismo, principalmente tendo no horizonte o período histórico que compreende a primeira metade do século XX. Uma vacuidade que em si abriga a inevitável referência ao objeto que outrora ocupou esse espaço vazio. A arte e a religião são impactadas pelo projeto moderno, de maneira que, à luz dos critérios impostos pela racionalidade engendrada na modernidade, 
ambas compartilham do relativo descrédito dedicado a tudo aquilo que não pode ser mesurado, a todas as instâncias que operam sob a égide da linguagem simbólica e ficcional. A religião conseguiu ser preservada como uma espécie de apêndice da moral, na categoria de uma narrativa de sentido meramente legitimadora da moralidade. Por outro lado, a arte conseguiu preservar na dimensão estética a capacidade de expressar em suas produções as diversas possibilidades de interpretação da realidade e da condição humana em sua relação com o mundo. Naturalmente, a leitura que a arte faz não se pretende portadora do peso de uma verdade científica, busca se expressar em uma aparência de verdade, justamente porque "a verdade que se mostra no relâmpago fugaz da experiência estética é ao mesmo tempo, porquanto concreta e presente, impossível de apreender" (WELLMER, 1993, p. 19 - tradução nossa). ${ }^{7}$

\section{Uma literatura pós-morte de Deus}

"A aventura da poesia, não a conclusão da filosofia, que mais verdadeiramente reflete a condição humana”, afirma Eagleton (2018, p.92). Uma afirmação corajosa e localizada na posição de quem observa o dilema humano diante do absoluto, especificamente pensando o cenário em que os românticos ditam a perspectiva de uma humanidade que ousou ter na arte o centro da sua subjetividade. A poesia aventura-se, assume sua despretensiosa ambição de brincar com as impressões do poeta a respeito do mundo, para que nessa aventura possa, pela linguagem, criar alguma relação de sentido além das fronteiras da objetividade discursiva. Já a filosofia nasce da ambição conclusiva de quem anseia por respostas. Ela nasce do ímpeto de quem elabora uma pergunta, de quem admite a crença primária na existência de uma possível resposta objetiva. É possível concordar com Eagleton quando se tem em mente que a imprecisão consciente da linguagem simbólica da poesia talvez diga mais sobre a condição humana do que a solidez filosófica presente na estrutura de perguntas e respostas. Quando se compreende na literatura uma "expressão de resposta ao vazio deixado pelas representações do sagrado" (SANTOS, 2012, p. 48), é possível examinar os

7 Do original: "La verdad que se muestra en el relampagueo fugaz de la experiencia estética es al mismo tiempo, por cuanto concreta y presente, imposible de captar." 
desdobramentos do anúncio nietzschiano da morte de Deus como um dos principais indícios da crise da modernidade.

Ao dessacralizar a verdade de uma concepção de valor absoluto, "a verdade primeira que era Deus também se dissolve" (TEIXEIRA, 2006, p. 212). Num olhar crítico para a sociedade burguesa europeia do seu tempo, Nietzsche percebe uma mudança de paradigma em curso, e, por conta disso, a sua crítica se expande na rejeição ao "absolutismo da verdade, do bem e do imperativo da razão" (SANZ, 2017, posição 72 - tradução nossa) ${ }^{8}$, representado na promessa iluminista de emancipação humana através da razão. O que se tinha naquela altura do século XIX era um tabuleiro com todas as peças se montando para formar a trágica figura das duas grandes guerras do século XX, fatores relevantes para se pensar a virada crítica da filosofia em relação ao estatuto da modernidade.

Eagleton (2018) menciona a respeito do Super-homem nietzschiano:

O Super-Homem, ou animal pós-humano, é aquele que se libertou dessas formas envergonhadas de religião conhecidas como Natureza, Razão, Homem e moral. Só esse animal audacioso pode perscrutar o Abismo do Real e encontrar na morte de Deus o nascimento de uma nova espécie de humanidade (EAGLETON, 2018, p. 147).

Essa liberdade das formas da religião se concretizaria, precisamente, quando se realizasse a libertação em relação a crença nos valores absolutos, nos fundamentos de sentido inato. O homem pós-humano, concebido por Nietzsche, abraçaria o Abismo da ausência de sentido do real, ressignificando a sua existência a partir da consciência de que a realidade suporta a nossa visão em perspectiva, a consciência de quem compreende o papel interpretativo do ser humano na atribuição de sentido para a realidade.

Eagleton (2018, p. 144) ainda consegue ser preciso quando argumenta que Nietzsche teria percebido que só poderíamos nos livrar da

8 Do original: "Lo que sí proporciona Nietzsche en su demoledora crítica es la pretensión misma: la pérdida del proyecto totalizador, la exaltación de la perspectiva y la irracionalidad frente al absolutismo de la verdad, del bien y del imperativo de la razón, la defensa de la multiplicidad y del dinamismo frente a la unidad y frente al carácter permanente, o la negación de cualquier valor trascendente a lo fenomenológico y de todo valor sacralizador y dominante de la palabra." 
figura de Deus quando descartássemos a ideia de um significado inato. Mas por que essa libertação seria necessária? O problema visto por Nietzsche era a constatação do ressentimento humano negando a realidade da vida, dos sentidos, do corpo e do mundo, sempre recorrendo a narrativas de uma realidade ideal distante e impalpável, cada vez mais envolvendo o ser humano numa fraca e danosa atitude diante da vida. Diante de todo esse panorama, com o declínio do poderio eclesiástico sobre as instituições sociais, também com as descobertas científicas daquela época, revelando as contradições cada vez mais aparentes entre o discurso religioso e o discurso científico, considerando ainda a perda de relevância de Deus nas esferas política e cultural, temos o sentido do anúncio da morte de Deus, não como um acontecimento metafísico a afetar um ser supremo e desconhecido numa determinada região do além, mas como o fato concreto de que na única dimensão em que temos a comprovada atuação, a da vida presente, o ideal desse Deus não estava mais no centro das atenções. É na cultura que Deus morre, e nós o matamos, como disse Nietzsche (2012): "Deus está morto! Deus continua morto! E nós o matamos! Como nos consolar, a nós, assassinos entre os assassinos?" (NIETZSCHE, 2012, p. 138).

Vattimo (1996, p. 170-173) entende a pós-modernidade em filosofia como um evento que começa com o anúncio de Nietzsche. O caminho para essa conclusão está em pensar a saída da modernidade acontecendo não pelos termos da própria modernidade, ou seja, não se trata de superar o moderno por outra categoria mais nova. A substituição constante do velho pelo novo permanece dentro do escopo moderno de pensamento. A saída pós-moderna também não se apoia em uma superação crítica, ela vai ao encontro de uma radicalização que finda no desaparecimento do elemento fundador das bases modernas, a verdade. "É com esta conclusão niilista que se sai de fato da modernidade, segundo Nietzsche. Pois a noção de verdade não mais subsiste e o fundamento não mais funciona" (VATTIMO, 1996, p. 173).

A literatura da primeira metade do século XX materializa na sua dimensão artística essa transição de paradigmas que se estenderá ainda pelas décadas seguintes, desde o advento das vanguardas europeias até a consolidação do modernismo. Especificamente sobre as obras de arte da primeira metade do século XX, Tillich afirma que: 
São expressões criativas das tendências destrutivas da cultura contemporânea. As grandes obras de arte visual, de música, poesia, literatura, arquitetura, dança e filosofia mostram em seus estilos o encontro com o não-ser, bem como a força de moldá-lo criativamente. Sem essa chave, a cultura contemporânea é uma porta fechada. Com esta chave, ela pode ser entendida como revelação da situação humana, tanto no mundo presente como no universo. Assim, o protesto presente na cultura contemporânea adquire significado teológico. (TILLICH, 2009, p. 88)

Depois dessa citação, somos instigados a depositar sobre a noção de estilo a incumbência de acolher as expressões criativas que refletem as tendências humanas diante da relação problemática com o mundo. É necessário também dar a devida atenção a esse encontro com o não-ser como fator fundamental para se compreender a substância desse período histórico na qualidade de uma "era da angústia - age of anxiety" (TILLICH, 1980, p. 35). Tillich define primariamente a angústia como "o estado no qual um ser tem consciência do seu possível não-ser" (TILLICH, 1980, p. 35 - tradução nossa) ${ }^{9}$, fazendo dessa consciência a respeito da própria finitude um elemento participante da própria constituição do ser. A angústia nasce principalmente atrelada ao conhecimento de que o não-ser não é algo abstrato, mas é uma parte da própria condição de ser. Diante disso é impossível não lembrar da afirmação de Kierkegaard (2011, p. 19) sobre o homem ser uma síntese de finitude e infinitude, ainda mais quando se tem em mente as possíveis influências do pensamento de Kierkegaard em Tillich (SILVA, 2014). Com a morte de Deus e a desconsideração de uma vida eterna num lugar além da realidade física do mundo, o não-ser se estabelece para a humanidade como uma realidade inescapável, uma condição inegociável da vida.

Enquanto a angústia expressa a nossa reação diante da certeza da própria finitude, a coragem, por outro lado, é um conceito que se traduz como a autoafirmação do ser apesar de tudo que vai de encontro a essa atitude afirmativa (TILLICH, 1980, p. 32) ${ }^{10}$. O ato de ser nos conduz à necessidade da coragem, a necessidade de se autoafirmar diante de tudo que obstrui a nossa autoafirmação. Quando entra em cena o con-

9 Do original: "The first assertion about the nature of anxiety is this: anxiety is the state in which a being is aware of its possible nonbeing."

10 Trecho original indiretamente mencionado: "Courage is self-affirmation 'in-spite-of', that is in spite of that which tends to prevent the self from affirming itself." 
ceito de desespero como um estado de desprovimento de esperança, ou ainda o desespero como uma espécie de vitória do não-ser (TILLICH, 1980 , p. 54-55) ${ }^{11}$, podemos pensar a coragem do desespero como a coragem de assumir a desesperança diante do não-ser, de abraçar a inevitável certeza de nossa finitude e expressar essa aceitação num ato de coragem. Poderia ser a arte ou, especificamente, a literatura, sobretudo nas produções a partir do decadentismo do final do século XIX, um espaço fecundo para a manifestação dessa coragem do desespero? Estaria o artista envolvido pelos impulsos incondicionais oriundos da resolução interior dessa angústia evidenciada pelo momento histórico vivido? Poderíamos entender a obra de Fernando Pessoa, em toda a sua complexidade criativa demonstrada com a diluição do eu na elaboração heteronímica, como uma literatura que traz em si a marca do desespero?

A queda do absolutismo, o progresso do liberalismo e da democracia, a ascensão de uma civilização técnica com sua vitória sobre todos os inimigos e sua própria desintegração inicial, estes são os pressupostos sociológicos para o terceiro período principal da angústia. Neste, a angústia da vacuidade e insignificação é dominante. Estamos sob a ameaça do não-ser espiritual (TILLICH, 1980, p. 61-62 - tradução nossa) ${ }^{12}$.

Tillich identifica períodos mais suscetíveis para a angústia em finais de era, períodos em que as transformações sociais são tão intensas que a conjuntura da vida se encaminha para novos padrões. Dentre os três períodos principais listados por ele estão: o final da Antiguidade Clássica, em que prevaleceu a angústia ôntica, relativa ao destino e à morte; o final da Idade Média, em que se manifestou mais fortemente a angústia moral da culpa e da condenação; e ao final do período moderno teríamos a angústia da vacuidade e da insignificação (TILLICH, 1980, p. 57). Esta última bastante devedora de todo o contexto que

11 Trecho original indiretamente mencionado: "Despair is an ultimate or "boundary-line" situation. One cannot go beyond it. Its nature is indicated in the etymology of the word despair: without hope. No way out into the future appears. Nonbeing is felt as absolutely victorious."

12 Do original: "The breakdown of absolutism, the development of liberalism and democracy, the rise of a technical civilization with its victory over all enemies and its own beginning disintegration these are the sociological presupposition for the third main period of anxiety. In this the anxiety of emptiness and meaninglessness is dominant. We are under the threat of spiritual nonbeing." 
vem sendo desenvolvido neste artigo quando nos referimos à perda da dimensão de profundidade da vida ocasionando a ruína do ideal de transcendência e suas consequências no modo como, coletivamente, significamos o mundo.

A angústia da insignificação é angústia pela perda da preocupação última, do significado que concede sentido a todos os sentidos. Esta angústia é despertada pela perda de um centro espiritual, de uma resposta, ainda que simbólica e indireta, para a questão do sentido da existência (TILLICH, 1980, p. 47 - tradução nossa) ${ }^{13}$.

O existencialismo é, para Tillich, a expressão dessa angústia da insignificação, bem como da tentativa de conciliar tal angústia e a coragem de ser como si mesmo. Reconhecendo também que o evento definitivo para toda a busca por sentido e para o desespero subjacente a ela é resumido no anúncio da morte de Deus, ainda no século XIX. À sombra desse momento filosófico, a arte, a literatura e a filosofia do século XX se constituem como uma produção corajosa, voltada para expressar a angústia dessa ausência de sentido por meio de uma desesperada atitude de autoafirmação, uma coragem de desespero (TILLICH, 1980 , p. 142-143). Sob este ponto de vista, podemos dizer que a literatura do pós-morte de Deus é uma literatura do desespero humano.

\section{Sensacionismo como coragem de desesperar}

Quando examinamos o modernismo português da geração pessoana, que muitas vezes se definia como uma vanguarda do próprio modernismo, um movimento que ousou pensar, "no mundo bem-comportado da poesia lusitana, o lirismo poético como essência mítica das coisas" (MOISÉS, 2009, p. 11), fica evidente a dificuldade de definição do próprio movimento. $\mathrm{O}$ terreno conceitual do modernista é pedregoso, pois o moderno é "ao mesmo tempo, caótico e coerente; irracionalista e racionalista; fluido e estático; fragmentário e organizado; aleatório e rigoroso; anárquico e hierárquico" (MARTINS, 2017, p. 18). Num

13 Do original: "The anxiety of meaninglessness is anxiety about the loss of an ultimate concern, of a meaning which gives meaning to all meanings. This anxiety is aroused by the loss of a spiritual center, of an answer, however symbolic and indirect, to the question of the meaning of existence." 
diálogo profundo com o contraditório, Pessoa via sua estética moderna recheada de ismos, tais como o interseccionismo, o paulismo, e principalmente o sensacionismo. No texto de apresentação de um dos livros que reúne suas anotações sobre o sensacionismo, podemos ler, nas palavras do editor,

que o Sensacionismo toma a sério a sua vocação de poética de síntese. Tanto é o movimento de um grupo como a poética de um indivíduo. Tanto afirma os valores poéticos do fim de século simbolista-decadentista como os do novo século cubista e futurista. Mas, apesar do seu teor paradoxal, o Sensacionismo consegue o prodígio de não perder o sentido, porque se mantém focado no conceito de sensação (PESSOA, 2015, p. 11).

O sensacionismo consiste na valorização da sensação e na fragmentação da personalidade, na desvalorização de uma identidade sólida para o artista, o distanciamento mais significativo entre o poeta e o eu-lírico. O modernismo, por sua vez, tomado ao pé da letra, tem a ver com moda, mudança, novidade. Ancorado na proposta de trazer o novo em cada manifestação cultural humana, vemos que "essa é uma exigência sublinhada pelo espírito da Modernidade” (MARTINS, 2017, p. 18). Na apresentação feita por Martins e Zenith aos textos de Pessoa, são citadas as palavras do poeta: "as condições da vida moderna, as peripécias políticas e sociais que em todos os estados se dão hoje, criam (...) um desejo furioso de novidade que é talvez o que na arte corresponde ao espírito revolucionário nas sociedades" (PESSOA, 2015, p. 10).

Entender a natureza singular da poesia pessoana no modernismo português é uma tarefa que requer o entendimento do contexto em que esse modernismo se desenvolve e, principalmente, o entendimento acerca dos pressupostos que marcam a ruptura com uma estética anterior e tornam aquela produção literária uma coisa nova e única. E aqui é preciso enfatizar o sensacionismo como o arranjo teórico que promove a orientação estética de Pessoa quando resolve afirmar a sua obra através de uma construção lírica de vários eus elaborados, conscientemente, com a riqueza de detalhes com que um romancista elabora seus personagens.

A estética sensacionista denuncia uma ressignificação do eu no mundo pela visão do poeta, de maneira que o eu não é encarado como algo sólido, definido e estável, mas como um resultado do acaso da vida, sem 
a ancoragem de um sentido maior que o defina, mantendo-se sempre arbitrário e volúvel. Diante de um eu que não tem mais fundamento metafísico, o poeta escolhe então assumir essa indefinição como sua atitude de coragem, autoafirmando esse eu diluído na exaltação de sua diluição.

Em diversas passagens em que se esforça para definir e organizar o seu projeto literário, Pessoa faz questão de valorizar a sensação, a manifestação sensorial como mecanismo principal de nossa apreensão do mundo, rejeitando qualquer referência que seja construída por narrativas de sentido extra-físico. Nas palavras do heterônimo Alberto Caeiro:

\section{XXXIX}

O mistério das coisas, onde está ele?

Onde está ele que não aparece

Pelo menos a mostrar-nos que é mistério?

Que sabe o rio e que sabe a árvore?

E eu, que não sou mais do que eles, que sei disso?

Sempre que olho para as coisas e penso no que os homens pensam delas, Rio como um regato que soa fresco numa pedra.

Porque o único sentido oculto das coisas

É elas não terem sentido oculto nenhum,

É mais estranho do que todas as estranhezas

E do que os sonhos de todos os poetas

E os pensamentos de todos os filósofos,

Que as coisas sejam realmente o que parecem ser

E não haja nada que compreender.

Sim, eis o que os meus sentidos aprenderam sozinhos: -

As coisas não têm significação: têm existência.

As coisas são o único sentido oculto das coisas.

(PESSOA, 2007, p. 79; 2020c, p. 719)

Também nas primeiras linhas de um dos seus esboços podemos ler que "toda a arte é a sobreposição às Coisas da nossa interpretação ou ideia delas" (PESSOA, 2015, p. 14). A obra de arte se converte na coisa própria do artista, na sua leitura das coisas do mundo. "A arte real é encontrar o ponto exato de contato entre as coisas e a nossa interpretação delas" (PESSOA, 2015, p. 14). 
Entendendo a arte como uma "expressão da individualidade", ciente de que "a individualidade é vaga e indecisa - ninguém se compreende a si próprio" (PESSOA, 2015, p. 26), Pessoa reafirma em seu manifesto sensacionista:

$1^{\circ}$ - A arte é uma interpretação da Vida. A Vida é incompreensível e complexa. Toda a arte que não for misteriosa e simples, portanto, errará o sentido à Vida, será falsa arte, uma má educação dos sentidos puros de artista. Não querer compreender a vida - querer exprimi-la apenas: eis a Arte (PESSOA, 2015, p. 26).

O sensacionista enxerga o caráter incompreensível e complexo da vida como motivo para a proposição de uma arte que seja sensível ao mistério que nos envolve a condição existencial e que seja simples no trato de uma já saturada noção de complexidade da vida. Quando ele propõe não querer compreender a vida, ele está propondo que não se busque obter através da arte respostas fechadas e definitivas para o fenômeno da existência, ele pressupõe sobre o ato de compreender uma atividade racional descabida para a hercúlea tarefa de delimitar a natureza misteriosa da vida. Exprimir, sem compromisso com nenhuma outra tarefa limitante, eis o domínio da arte para Pessoa. Errar o sentido da vida é um risco que nos acomete quando se busca a objetividade de uma resposta definitiva para as questões que o mistério de tudo preserva. Errar o sentido à vida pode inclusive ser uma consequência direta de lhe atribuir um sentido, o poeta tem consciência disso. Em função dessa consciência, o sensacionista recusa enfaticamente toda consideração de importância a estímulos que não provenham das sensações. "O único sentido íntimo das coisas / É elas não terem sentido íntimo nenhum", declaram os versos do mestre dos heterônimos, Alberto Caeiro (PESSOA, 2007, p. 39), enquanto Pessoa ele-mesmo teoriza em seus escritos: "Considerado como metafísica, o Sensacionismo visa a não compreender o universo. A realidade é a incompreensibilidade das coisas. Compreendê-las é não compreendê-las" (PESSOA, 2015, p. 73).

Ao ter na sua proposta estética uma teoria que se volta para uma concepção própria de arte, de realidade e de subjetividade, Pessoa tempera a sua poética com profundas inquietações existenciais, que por sua vez se afinam com o que seriam as preocupações humanas no século 
XX e, consequentemente, no modernismo. Se o poeta modernista é um artista que se alimenta da angústia, poderíamos pensar a literatura modernista como uma arte que se edifica no desespero humano frente à vacuidade de Deus. Se essa literatura se alimenta liricamente da angústia e manifesta a sua coragem na medida em que se assume desesperada, como repensar a relação entre religião e arte? Aposto aqui no reconhecimento do caráter existencial da preocupação artística, traduzindo-se na percepção de sua vinculação religiosa, como algo que tem o poder de enriquecer a nossa perspectiva na hora de interpretar o mundo e conduzir nossas mais profundas inquietações a novos debates.

(...) Quanto mais eu sinta, quanto mais eu sinta como várias pessoas, Quanto mais personalidades eu tiver,

Quanto mais intensamente, estridentemente as tiver,

Quanto mais simultaneamente sentir com todas elas,

Quanto mais unificadamente diverso, dispersadamente atento,

Estiver, sentir, viver, for,

Mais possuirei a existência total do universo,

Mais completo serei pelo espaço inteiro fora,

Mais análogo serei a Deus, seja ele quem for,

Porque, seja ele quem for, com certeza que é Tudo,

E fora d'Ele há só Ele, e Tudo para Ele é pouco. (...)

(PESSOA, 2010, p. 224)

\section{Conclusão}

A escolha da sensação como centro do ideal estético pessoano pode ser retratada como uma escolha desesperada, uma escolha que parte de uma relação angustiada com o mundo, cujo desespero em relação à existência visa se apegar ao que pode ser acessível e imediato na percepção humana, as suas próprias sensações. A consideração do cenário pós-morte de Deus nos permite pensar a arte como o refúgio no qual o artista busca conforto, enquanto expressa suas inquietações existenciais. Tais inquietações, porquanto intimamente ligadas à preocupação última, revelam o potencial religioso da obra de arte. Em outras palavras, a poesia se torna um instrumento autoafirmativo por onde o poeta se manifesta em atos de coragem, a despeito da angústia que sente no confronto com a sua própria finitude, diante do desamparo metafísico ocasionado pela desconfiança dirigida para o ideal de 
um deus absoluto, de uma verdade inabalável e de um fundamento de sentido para sua vida.

A expressão literária em si tem a possibilidade de ser ao mesmo tempo um esforço narrativo de interpretação da realidade e uma expressão da experiência religiosa do humano diante do mundo, do humano em sua concepção de sentido de mundo, algo que se pode afirmar sobre a poesia de Pessoa, quando examinamos a bagagem discursiva que ela comunica. Nela a consequência mais evidente da angústia da vacuidade e insignificação é a perda do fundamento da própria identidade, algo expresso na variedade de heterônimos que se dedicam a reproduzir formas possíveis de sentir a realidade, ou como ele diz, "sentir tudo de todas as maneiras" (PESSOA, 2020c, p. 1021). Como o ato mais corajoso de desespero, resta apenas "abolir o dogma da personalidade: cada um de nós deve ser muitos. A arte é aspiração do indivíduo a ser o universo. O universo é uma coisa imaginada: a obra de arte é um produto de imaginação" (PESSOA, 2015, p. 73).

\section{Referências}

EAGLETON, Terry. A morte de Deus na cultura. Trad. Clóvis Marques. $2^{\mathrm{a}}$ ed. Rio de Janeiro: Record, 2018.

KIERKEGAARD, Sören. O Desespero Humano. Trad. Fransmar Costa Lima. $2^{\mathrm{a}}$ reimp. São Paulo: Martin Claret, 2011.

MARTINS, Fernando Cabral. Introdução ao Estudo de Fernando Pessoa. Cotia, SP: Ateliê Editorial, 2017.

MOISÉS, Massaud. Fernando Pessoa: O Espelho e a Esfinge. $3^{\text {a }}$ ed. rev. e aum. São Paulo: Cultrix, 2009.

NIETZSCHE, Friedrich. A Gaia Ciência. Trad. Paulo César de Souza. $1^{\mathrm{a}}$ ed. $7^{\mathrm{a}}$ reimpressão. São Paulo: Companhia das Letras, 2012.

PESSOA, Fernando. Obra Completa de Fernando Pessoa V: Escritos sobre Arte e Literatura (Edição Definitiva). Edição Kindle, 2020.

Obra Completa de Fernando Pessoa VII: Escritos sobre Filosofia (Edição Definitiva). Edição Kindle, 2020a.

Obra Completa de Fernando Pessoa VIII: Escritos e fragmentos autobiográficos (Edição Definitiva). Edição Kindle, 2020b.

Kindle, 2020c.

Obra Poética Completa: Volume Único (Edição Definitiva). Edição 
. Poemas Completos de Alberto Caeiro. São Paulo: Martin Claret, 2007.

. Sobre o Orpheu e o Sensacionismo. Ed. Fernando Cabral Martins e Richard Zenith. Porto: Assírio \& Alvim, 2015.

SANZ, Hector Martinéz. Lenguaje, verdad y hermenéutica posmoderna: $\mathrm{H}$. G. Gadamer y G. Vattimo. $1^{\mathrm{a}}$ Ed. Madrid: Edição Kindle, 2017.

SILVA, Elias Gomes da. Kierkegaard e Tillich: possibilidades que se abrem. Revista Eletrônica Correlatio v. 13, n. 26 - dezembro de 2014.

TEIXEIRA, Evilázio. Pós-modernidade e niilismo - um diálogo com Gianni Vattimo. ALCEU - v.7, no 13, p. 209-224. Jul./dez. de 2006.

TILLICH, Paul. Religion and Secular Culture (1946). In.: PALMER, Michael (Ed.). Paul Tillich's Main Works - volume 2: writings in the Philosophy of Culture. Berlin; New York: De Gruyter, 1990, p. 197-207.

. Teologia da cultura. Trad. Jaci Maraschin. São Paulo: Fonte Editorial, 2009.

. Teologia Sistemática. Trad. Getúlio Bertelli e Geraldo Korndörfer. $8^{\text {a }}$ ed. rev. São Leopoldo: Sinodal, 2019.

. Textos Selecionados. Ed. Eduardo de Proença. São Paulo: Fonte Editorial, 2020.

. The Courage to Be. Ed. Hannah Tillich. New Haven \& London Yale University Press, 1980.

VATTIMO, Gianni. O Fim da Modernidade: niilismo e hermenêutica na cultura pós-moderna. Trad. Eduardo Brandão. São Paulo: Martins Fontes, 1996.

WELLMER, Albrecht. Sobre la dialéctica de modernidad y postmodernidad: La crítica de la razón después de Adorno. Traducción de José Luis Arántegui. Madrid: Visor Distribuciones, 1993.

Submetido em: 10-1-2022

Aceito em: 19-1-2022 